Guest Editorial, part of a Special Feature on Social Learning in Water Resources Management

\title{
The Growing Importance of Social Learning in Water Resources Management and Sustainability Science
}

\author{
Claudia Pahl-Wostl $^{1}$, Erik Mostert $^{2}$, and $\underline{\text { David Tàbara }}^{3}$
}

Key Words: adaptive management; European Water Framework Directive; social learning; stakeholder participation; water resources management

The perceptions of what is required for sustainable water resources management and sustainability science in general have undergone major changes over the past decade. Initially, water resources management followed an instrumental "prediction and control" approach, dominated by technical endof-pipe solutions. Pollution control, for example, relied primarily on waste water treatment instead of source control, and flood management was based on dykes and reservoirs rather than non-structural measures such as land-use zoning. This approach has yielded important results, but it came at a price. In many places, the natural dynamics of the river environment have been destroyed. Moreover, this approach no longer works very well. It cannot adequately deal with the growing uncertainties, increasing rates of change, different stakeholder perspectives, and growing interdependence that are characteristic for today's resource management issues. What we need then is a new understanding of sustainable water resource management as a societal search and learning process (e.g., PahlWostl 2002, Wals 2007)

This new understanding of resource management ties in with recent approaches in the policy sciences. The introduction of the term "governance" signalled a change in thinking about the nature of policy. The notion of government as the single decision-making authority exerting sovereign control over its citizens has been replaced by multi-scale, polycentric governance approaches that recognize the contribution of a large number of stakeholders, functioning in different institutional settings. Governance takes into account the increasing importance of basically non-hierarchical modes of governing, where non-state and private corporate actors (formal organizations) participate in the formulation and implementation of public policy. It thus encompasses a broad range of processes related to the coordination and steering of a wide range of actors by formal and informal institutions (Mayntz 1998, Pahl-Wostl et al. in press). A governance perspective places a strong emphasis on social learning as an essential element of policy development and implementation (Folke et al. 2005, Pahl-Wostl et al. 2007).

Within a governance perspective, social learning is an essential element of policy development and implementation (Folke et al. 2005, Pahl-Wostl et al. 2007). The emphasis is now moving from the need to simply 'know more' and deploying even more information to policy and expert circles to developing adaptive cross-sectoral capacities and new types of knowledge to respond adequately to the changing dynamics of social-ecological systems in concrete contexts of action. The problem that we face when we deal with sustainability lies not so much in our lack of understanding of the functioning of ecological systems, but in our lack of understanding of the governance and cultural systems and how they are structured and managed and interact with ecological systems, and how we produce science and knowledge for policy. Social learning entails developing new relational capacities, both between social agents, in the form of learning how to collaborate and understand others' roles and capacities differently, and also between social-ecological systems (sustainability learning). New institutional arrangements are needed to structure the more sustainable relationships, based on new framings of the issues at stake and the agents involved. Therefore, the problem lies in developing new identities, as well as institutions and individual capacities, that are

${ }^{1}$ University of Osnabrück, ${ }^{2}$ Delft University of Technology, ${ }^{3}$ Universität Autònoma de Barcelona 
more socially and ecologically robust with the common goal of sustainability.

Through its sixth Framework Programmes for research and technological development, key action water, the European Commission invested heavily in water-related research. A major impetus for this was the European Water Framework Directive (WFD), which entered into force in 2000. The WFD introduces the following innovative elements into European Water Policy:

- An integrated approach expanding the scope of water protection to all waters, surface waters, and groundwater;

- The hydrological principle where water management is based on river basins;

- The obligation to achieve a "good status" by 2015;

- A "combined approach" of emission limit values and quality standards;

- Getting the prices right by introducing the principle of cost recovery;

- Getting citizens involved more closely by prescribing public participation in the development and implementation of the WFD.

The WFD poses a considerable challenge for water management in the different European countries. Its implementation requires change and innovation, and thus, social learning to achieve the envisaged goals.

The contributions in this special feature strongly underline the importance of social learning in water governance and sustainable water resource management. They are based on work developed in the context of two European research projects: HarmoniCOP and SLIM. The main objectives of the HarmoniCOP (Harmonizing Collaborative Planning) project were to increase the understanding of participatory river-basin management in Europe, to generate practical, useful information and improve the scientific basis of social learning and the role of ICT tools in river-basin management, and to support the implementation of the European WFD. The aim of the SLIM (Social Learning for the Integrated Management and sustainable use of water at catchment scale) project was to contribute to building the capacity of policy makers at all levels to create contexts conducive to stakeholders' managing and regenerating watersheds in a locally interactive process.

In the first contribution of this special feature, PahlWostl et al. (2007) present the concept for social learning and collaborative governance developed in the European project HarmoniCOP. The project developed a new conceptual framework to capture the essential processes of multi-level social learning in river-basin management. The focus is on learning of the social entity as a whole. The framework is characterized by a broad understanding of social learning that is rooted in the more interpretative strands of the social sciences, emphasizing the context dependence of knowledge. The role of frames and boundary management in processes of learning at different levels and time scales is investigated. The foundation of social learning as investigated in the HarmoniCOP project is multiparty collaboration processes that are perceived to be the nuclei of learning processes. Such processes take place in networks or "communities of practice" and are influenced by the governance structure in which they are embedded.

Mostert et al. (2007) present and analyze 10 case studies of participatory river-basin management that were conducted as part of the European HarmoniCOP project. The case studies show that social learning in river-basin management is not an unrealistic ideal. Factors that support and prevent social learning are identified, and recommendations are derived from them.

Enserink et al. (2007) highlight the importance of national cultures, and report a comparative analysis of the influence of national cultures in the different countries. They base their analyses on a national approach and background studies that examined and evaluated both historical and recent experiences that exist across Europe in relation to public participation and water management.

Borowski et al. (2008) go into depth in a comparison of a German and a French case study basin. They show how social learning is impeded by spatial misfits between participatory and decision-making institutions. They also demonstrate that river-basinscale institutions or actors linking parallel structures are essential for promoting river basins as 
management entities and for encouraging social learning between actors at the river-basin scale.

In their synthesis paper, Tàbara and Pahl-Wostl (2007) address the importance of the content and direction of change for social learning. They contribute to the normative discussion on sustainability learning, and provide a theoretical integrative framework intended to underly the main components and interrelations of what learning is required for social learning to become sustainability learning.

The paper by Ison et al. (2007) presents the results of the SLIM project for the case of Scotland. It underlines the role of historical and contextual factors in creating possibilities for social learning, understood as achieving concerted action in complex and uncertain situations, showing that social learning indeed occurred in the development of the Scottish Water Bill, but not necessarily as a result of a purposeful design.

The contribution of Steyaert and Ollivier (2007) is also a result of the SLIM project. They analyze the text of the WFD and conclude that the WFD reflects a particular and contested current of thought in ecosystems science that focuses on ecosystems status and stability. To engage the stakeholders in a social-learning process and promote adaptive management, a more "functionalist" approach is needed that enables the stakeholders to identify the water problems together and make feasible collective choices.

The different contributions in this special feature focus on the water management situation in Europe. Nonetheless, we believe that the general concepts and insights are relevant for other parts of the world as well. Furthermore, the paradigm shift observed in water management is of interest for sustainability science in general, where goal-oriented, instrumental approaches have been complemented by a stronger emphasis on process-based approaches. We strongly encourage readers to provide feedback on individual papers to engage in a learning and development process on this important theme.

Responses to this article can be read online at: http://www.ecologyandsociety.org/voll3/iss 1/art24/responses/

\section{Acknowledgments:}

The work presented in this paper was funded by the European Commission (Contract no EVK1CT-2002-00120). We thank all contributing authors for their efforts and enthusiasm in developing this special feature with us.

\section{LITERATURE CITED}

Borowski, I., J.-P. Le Bourhis, C. Pahl-Wostl, and B. Barraqué. 2008. Spatial misfit in participatory river basin management: effects on social learning. A comparative analysis of German and French case studies. Ecology and Society 13(1): 7. [online] URL: http://www.ecologyandsociety.org/vol13/iss1/ art7l.

Enserink, B., M. Patel, N. Kranz, and J. Maestu. 2007. Cultural factors as co-determinants of participation in river basin management. Ecology and Society 12(2): 24. [online] URL: http://www.e cologyandsociety.org/vol12/iss2/art24/.

Folke,C., T. Hahn, P. Olsson, and J. Norberg. 2005. Adaptive governance of social-ecological systems. Annual Review of Environment and Resources 30:8.1-8.33.

Ison, R., and D. Watson. 2007. Illuminating the possibilities for social learning in the management of Scotland's water. Ecology and Society 12(1): 21. [online] URL: http://www.ecologyandsociety.org/vol12/ iss1/art21/.

Mayntz, R. 1998. New challenges to governance theory. Jean Monet Chair Papers No. 50, European University Institute, Florence, Italy.

Mostert, E., C. Pahl-Wostl, Y. Rees, B. Searle, D. Tàbara and J. Tippet. 2007. Social learning in European river-basin management: barriers and fostering mechanisms from 10 river basins. Ecology and Society 12(1): 19. [online] URL: http://www.e cologyandsociety.org/vol12/iss1/art19/.

Pahl-Wostl, C. 2002. Towards sustainability in the water sector: the importance of human actors and 
processes of social learning. Aquatic Sciences 64:394-411.

Pahl-Wostl, C. 2007. The implications of complexity for integrated resources management. Environmental Modeling and Software 22:561-569.

Pahl-Wostl, C., M. Craps, A. Dewulf, E. Mostert, D. Tàbara, and T. Taillieu. 2007. Social learning and water resources management. Ecology and Society 12(2): 5. [online] URL: http://www.ecology andsociety.org/vol12/iss2/art5/.

Pahl-Wostl, C., J. Gupta, and D. Petry. 2008. Governance and the global water system: towards a theoretical exploration. Global Governance 14, in press.

Steyaert, P., and G. Ollivier. 2007. The European Water Framework Directive: how ecological assumptions frame technical and social change. Ecology and Society 12(1): 25. [online] URL: http: //www.ecologyandsociety.org/vol12/iss1/art25/.

Tàbara, J. D., and Pahl-Wostl, C. 2007. Sustainability learning in natural resource use and management. Ecology and Society 12(2): 3. [online] URL: http://www.ecologyandsociety.org/vol12/iss2/ art3/.

Wals,A. E. J., editor. 2007. Social learning towards a sustainable world. Wageningen Academic Publishers, Wageningen, The Netherlands. 